\title{
The Effect of Female College Student's Stress Level on Premenstrual Syndrome
}

\begin{abstract}
The purpose of this study is to understand the relationship between female college students' stress level and premenstrual syndrome so that it can provide baseline data on how to cope with the syndrome. The study subjects are 250 female college students in Gyungbook area. This study chose 199 appropriate subjects and collected data. As per general menstrual phases, this study investigated the age when one had her first period, regularity and duration of period, and amount of bleeding. It used a measurement tool to measure stress level and premenstrual syndrome.

Most of the subjects experienced their first period before the age of 13. The menstrual period was irregular with the duration of less than 7 days. 123 subjects had normal amount of bleeding. 121 subjects were experiencing high level of stress over 2.4. The correlation between the level of stress and premenstrual syndrome factors showed significant static correlation for each factor. Especially, the correlation between digestive system and response of autonomic nervous system was .996 and negative emotion and behavioral change was .635, and negative emotion and pain was .614 which were relatively high. The regression analysis of factors of premenstrual syndrome depending on the subjects' stress level indicated that response of autonomic nervous system had the biggest effect in the low stress group while behavioral change, negative emotion, pain, decreased concentration, water congestion, response of autonomic nervous system, and skin change had the biggest effect in the high stress group with statistical significance. Based on the result, it can be said that higher premenstrual stress is closely related to the premenstrual syndrome one experiences for some female college students.
\end{abstract}

Key words: Stress Index; Premenstrual Syndrome; Menstrual Phase; Circadian Rhythm

\author{
Eun Young Kim, Ju Han Bae \\ Gumi university, Gumi, Korea \\ Received : 03 May 2014 \\ Revised : 07 July 2014 \\ Accepted : 03 September 2014 \\ Address for correspondence \\ Ju Han Bae, PT, Ph.D \\ Department of Physical Therapy, Gumi \\ University, 37 Yaeun-ro, Gumi-si, \\ Gyeongbuk, Korea \\ Tel : 82-54-440-1249 \\ E-mail:bjhan4@gumi.ac.kr
}

\section{INTRODUCTION}

Premenstrual syndrome is emotional, behavioral, and physical symptoms that occur repeatedly during progestational phase in general(1). International Classification of Diseases, 10th Revision(ICD-10) defines it can be diagnosed as premenstrual syndrome when one satisfies one of the following 7 symptoms only during the progestational phase; minor psychological discomfort, bloating, weight gain, breast tenderness, muscular tension or aches, poor concentration, changes in appetite(2).

Premenstrual syndrome starts in the late 10 s or early 20s and the symptoms include the above physical changes as well as psychological changes such as emotional sway, depression, anxiety, and aggressiveness(3). Kim et al. report that it can cause difficulties in performing everyday activities(4). Jeong et al. report that $83.3 \%$ of female college students experience more than one premenstrual syndrome(5), and $54.6 \%$ of them experience physical symptoms and the symptoms disturb their work or study more than once or twice a month.

Premenstrual syndrome occurs due to interaction ofvarious factors such as biological factors(6) including ovarian function caused by changes in estrogen and 
progesterone, prostaglandin, or nutritional unbalance, or psychological conflict, environmental factor, stress, neurosis, perfectionism, gender role, and depression(7). In addition, one U.S. report says that premenstrual syndrome patients experience 5 times decreased productivity and increased visits to medical institutions which results in medical expense over $\$ 500$ in 2 years compared to the ones without the syndrome and it increases health and economic burden(8). Gu et al.(9) report that $6.2 \%$ are serious cases that they cannot do any house chores or work. According to the studies on menstruation, stress is the major factor that influences menstruation symptoms and is a variable that describes menstruation phase(10), and there are various researches accordingly(11, 12).

Therefore, this study understands that socio-psychological factors along with biological factors interact with physiological factors and affect female's premenstrual syndrome in the long run. Eventually, the treatment methods should consider the both biological and socio-psychological factors at the same time. In addition, women should understand their own body and be able to manage their health. This study tries to suggest baseline data to understand premenstrual syndrome and stress level which is closely related to one's experience in the society, culture, and interpersonal relationship so that women can properly respond according to their circadian rhythm.

\section{METHODS}

\section{Subjects}

This study chose 250 female college students at $G$ University in Gyungsangbuk-do. The study was conducted for 5 weeks from September 2nd to October 4th, 2014. It conducted the experiment on 199 subjects after excluding the ones who were in appropriate for statistical processing. The subjects understood the purpose of the study and signed an agreement to participate in the experiment.

\section{Measurement Equipment}

As general menstruation phase characteristics, this study investigated the age when one had her first period, regularity and duration of period, and amount of bleeding. It used a measurement tool to measure stress level and premenstrual syndrome.

\section{Stress level measurement tool}

This study used Brief Encounter Psycho-Social Instrument Korean version(BEPSI-K) and the level of limitation in performing everyday activities due to menstruation pain. BEPSI-K measures the amount of stress related to everyday incidents. It asks 5 stress-related questions and the responder gives 1 to 5 points using Likert's scale depending on how the subject feels. After measuring, it calculates stress index(BEPSI) after dividing the sum by the number of questions. BEPSI classifies the stress level into high stress $(\geq 2.4$ ), medium stress(1.3-2.4), and low stress $(\leq 1.3)$. Each question asks the type of psychological health and measures the status within the latest one month(13). Cronbach $\alpha$ for stress level measurement tool is .835 .

\section{Premenstrual syndrome measurement tool}

The symptoms of premenstrual syndrome were measured by 49 questions that were revised from 47 questions of Menstrual Distress Questionnaire(MDQ).

Table 1. Categories of premenstrual syndrome factors

\begin{tabular}{lccc}
\hline \multicolumn{1}{c}{ Factor Categories } & $\begin{array}{c}\text { Questions that belong to } \\
\text { each factor category }\end{array}$ & $\begin{array}{c}\text { Total number } \\
\text { of questions }\end{array}$ & Reliability \\
\hline 1. Negative emotion & $10,11,12,13, \quad 14,15,16,17,18$ & 9 & cronbach $\alpha$ \\
2. Digestive system change & 44,45 & 2 & $=.909$ \\
3. Behavioral change & $1,2,3,4,5, \quad 6,7,8,9$ & 9 & \\
4. Pain & $19,20,21,22,23,24,25$ & 7 & \\
5.Decreased concentration & $26,27,28,29, \quad 30,31,32,33$ & 8 \\
6. Water congestion & $34,35,36,37$ & 4 \\
7. Skin change & $46,47,48,49$ & 6 & \\
8. Response of autonomic nervous system & $38,39,40,41,42,43$ & 4
\end{tabular}


The questions were divided into 7 categories including behavioral change, negative emotion, pain, decreased concentration, water congestion, skin change, and response of autonomic nervous system. Each symptom could be indicated as 1 being no symptom' to 5 being 'very severe'. The total score was minimum of 49 to maximum of 245 , and the higher the score, the more severe the symptoms(15). In addition, each question was classified into factor categories. They were categorized into 8 factor categories; negative emotion, digestive system change, behavioral change, pain, decreased concentration, water congestion, skin change, and response of autonomic nervous system(Table 1). Cronbach $\alpha$ of the premenstrual syndrome measurement tool was .909 .

\section{Data Analysis}

The collected data was analyzed using SPSS 18.0 and the following analysis methods were used. Frequency and percentage were used to understand general phase of menstruation and stress level of the subjects. Factor analysis on premenstrual syndrome measurement tool was conducted, and reliability of stress measurement tool and premenstrual syndrome measurement tool was analyzed. Peason's Correlation Coefficients was used to understand the correlation between the factors of premenstrual syndrome depending on the stress level. Regression analysis on the stress level and premenstrual syndrome was conducted.

\section{RESULTS}

\section{General Characteristics of the Subjects}

In terms of general menstruation phase, majority of the subjects(116 subjects, 58.3\%) experienced their first period when they were less than 13 years old, 69(34.7\%) experienced between 14 and 15 years old, and 14(7\%) experienced after 16 years old. In terms of menstruation period, majority of them(112 subjects, 56.3\%) had irregular period and 87(43.7\%) had regular period. In terms of duration of period, 182(91.5\%) were less than 7 days and 17(8.5\%) were over 8 days. In terms of amount of bleeding, 123(61.8\%) were normal, 81(30.7\%) were excessive, and 15(7.5\%) were little. In terms of stress level during period, $121 \mathrm{sub-}$ jects(60.8\%) were experiencing high level of stress over $2.4,71(35.7 \%)$ were experiencing medium level of stress which is between 1.3 and 2.3, and 7(3.5\%) were experiencing low level of stress.

\section{Correlation between stress and premenstrual syn- drome}

Correlation between the stress level and the factors of premenstrual syndrome which are negative emotion, digestive system change, behavioral change, pain, decreased concentration, water congestion, skin change, and response of autonomic nervous system is very significant static correlation as shown in(Table $2)(p<.01)$. The correlation coefficient between the stress level and the factors of premenstrual syndrome

Table 2 General Characteristics of the Subjects

$(n=199)$

\begin{tabular}{|c|c|c|c|}
\hline & Characteristics & Classification & Number of subject (\%) \\
\hline \multirow{10}{*}{ Menstruation Phase } & \multirow{3}{*}{ Age of first period(years old) } & less than 13 & $116(58.3)$ \\
\hline & & $14-15$ & $69(34.7)$ \\
\hline & & Over 16 & $14(7.0)$ \\
\hline & \multirow{2}{*}{ Menstruation cycle } & Regular & $87(43.7)$ \\
\hline & & Irregular & $112(56.3)$ \\
\hline & \multirow{2}{*}{ Duration of menstruation period } & Less than 7 days & 182(91.5) \\
\hline & & Over 8 days & $17(8.5)$ \\
\hline & \multirow{3}{*}{ Amount of bleeding } & little & $15(7.5)$ \\
\hline & & medium & 123(61.8) \\
\hline & & excessive & $81(30.7)$ \\
\hline \multirow{3}{*}{ Stress level } & \multirow{3}{*}{ Stress level } & Low stress & $7(3.5)$ \\
\hline & & Medium stress & $71(35.7)$ \\
\hline & & High stress & $121(60.8)$ \\
\hline
\end{tabular}


was between maximum of .966 and minimum of .199 . Digestive system and response of autonomic nervous system showed the highest static correlation with the correlation coefficient of .966. Negative emotion and behavioral change was .635 , and negative emotion and pain was .614, which showed high static correlation.

Table 3. Correlation between stress and factors of premenstrual syndrome

\begin{tabular}{|c|c|c|c|c|c|c|c|c|c|}
\hline & \multirow[b]{2}{*}{ Stress } & \multicolumn{7}{|c|}{ Premenstrual Syndrome } & \multirow[b]{2}{*}{$\begin{array}{c}\text { Response of } \\
\text { autonomic } \\
\text { nervous system }\end{array}$} \\
\hline & & $\begin{array}{l}\text { Negative } \\
\text { emotion }\end{array}$ & $\begin{array}{l}\text { Digestive } \\
\text { system } \\
\text { change }\end{array}$ & $\begin{array}{l}\text { Behavioral } \\
\text { change }\end{array}$ & Pain & $\begin{array}{l}\text { Decrease } \\
d \text { con- } \\
\text { centration }\end{array}$ & $\begin{array}{l}\text { Water } \\
\text { conges- } \\
\text { tion }\end{array}$ & $\begin{array}{l}\text { Skin } \\
\text { change }\end{array}$ & \\
\hline Stress & - & & & & & & & & \\
\hline Negative emotion & $.518^{* * *}$ & - & & & & & & & \\
\hline $\begin{array}{c}\text { Digestive system } \\
\text { change }\end{array}$ & $.359^{* * *}$ & $.470^{* * *}$ & - & & & & & & \\
\hline Behavioral & $.486^{* * *}$ & $.635^{* * *}$ & $.449^{* * *}$ & - & & & & & \\
\hline change & $.376^{* * *}$ & $.614^{* * *}$ & $.584^{* * *}$ & $.482^{* * *}$ & - & & & & \\
\hline $\begin{array}{c}\text { Pain } \\
\text { Decreased }\end{array}$ & $.401^{* * *}$ & $.516^{* * *}$ & $.540^{* * *}$ & $.497^{* * *}$ & $.521^{* * *}$ & - & & & \\
\hline concentration & $.341^{* * *}$ & $.334^{* * *}$ & $.199^{* * *}$ & $.379^{* * *}$ & $.279^{* * *}$ & $.302^{* * *}$ & - & & \\
\hline Water congestion & $.280^{* * *}$ & $.445^{* * *}$ & $.385^{* * *}$ & $.300^{* * *}$ & $.419^{* * *}$ & $.366^{* * *}$ & $.282^{* * *}$ & - & \\
\hline $\begin{array}{l}\text { Skin change } \\
\text { response of } \\
\text { autonomic nerv- } \\
\text { ous system }\end{array}$ & $.364^{* * *}$ & $476^{* * *}$ & $.966^{* * *}$ & $.462^{* * *}$ & $.574^{* * *}$ & $.560^{* * *}$ & $.241^{* *}$ & $.452^{* * *}$ & - \\
\hline
\end{tabular}

\section{Regression analysis of stress and premenstrual syndrome}

The regression analysis result of premenstrual syndrome according to the level of stress is as follows(Table 4). The factor of response of autonomic nervous system in the low stress group showed $B=-$ 7.396( $\beta=-.958$ ) with $91.7 \%$ explanatory power and was statistically significant( $\mathrm{p}<.001)$. In addition, behavioral change in the high stress level showed $\mathrm{B}=.497(\beta=0.511)$ with $21.7 \%$ explanatory power,
$\mathrm{B}=0.661(\beta=0.554)$ with $30.7 \%$ explanatory power for negative emotion, $B=.454(\beta=0.390)$ with $15.2 \%$ explanatory power for pain, $B=0.460(\beta=.353)$ with $12.5 \%$ explanatory power for decreased concentration, $\mathrm{B}=0.787(\beta=0.322)$ with $10.4 \%$ explanatory power for water congestion, $\mathrm{B}=.425(\beta=.361)$ with $13.0 \%$ explanatory power for response of autonomic nervous system, $B=.357(\beta=.319)$ with $10.2 \%$ explanatory power for skin change. All were very significant statistically ( $p<.001)$. 
Table 4. Regression analysis of stress and premenstrual syndrome

\begin{tabular}{|c|c|c|c|c|c|c|}
\hline & & B & $\beta$ & $\mathrm{R}^{2}$ & t & $\mathrm{p}$ \\
\hline \multirow{7}{*}{$\begin{array}{l}\text { Low stress - } \\
\text { Symptom }\end{array}$} & Behavioral change & -2.315 & -2.315 & -2.315 & -2.315 & -2.315 \\
\hline & Negative emotion & -2.604 & -2.604 & -2.604 & -2.604 & -2.604 \\
\hline & Pain & -3.631 & -3.631 & -3.631 & -3.631 & -3.631 \\
\hline & Decreased concentration & -4.792 & -4.792 & -4.792 & -4.792 & -4.792 \\
\hline & Water congestion & -1.563 & -1.563 & -1.563 & -1.563 & -1.563 \\
\hline & Response of autonomic nervous system & -7.396 & -7.396 & -7.396 & -7.396 & -7.396 \\
\hline & Skin change & -1.250 & -1.250 & -1.250 & -1.250 & -1.250 \\
\hline \multirow{7}{*}{$\begin{array}{l}\text { Medium stress } \\
\text {-Symptom }\end{array}$} & Behavioral change & .336 & .336 & .336 & .336 & .336 \\
\hline & Negative emotion & .074 & .074 & .074 & .074 & .074 \\
\hline & Pain & .224 & .224 & .224 & .224 & .224 \\
\hline & Decreased concentration & .106 & .106 & .106 & .106 & .106 \\
\hline & Water congestion & .464 & .464 & .464 & .464 & .464 \\
\hline & Response of autonomic nervous system & .313 & .313 & .313 & .313 & .313 \\
\hline & Skin change & .120 & .120 & .120 & .120 & .120 \\
\hline \multirow{7}{*}{$\begin{array}{l}\text { High stress } \\
\text {-Symptom }\end{array}$} & Behavioral change & .497 & .497 & .497 & .497 & .497 \\
\hline & Negative emotion & .661 & .661 & .661 & .661 & .661 \\
\hline & Pain & .454 & .454 & .454 & .454 & .454 \\
\hline & Decreased concentration & .460 & .460 & .460 & .460 & .460 \\
\hline & Water congestion & .787 & .787 & .787 & .787 & .787 \\
\hline & Response of autonomic nervous system & .425 & .425 & .425 & .425 & .425 \\
\hline & Skin change & .357 & .357 & .357 & .357 & .357 \\
\hline
\end{tabular}

\section{DISSCUSSION}

Women experience repetitive physical and psychological symptoms during menstruation period. Especially, premenstrual syndrome results in decreased self-esteem and stress tolerance which can cause serious problem for one' s own self as well as family and social relationship(16). The purpose of this study is to understand female college students' general characteristics of menstruation and stress level during menstruation period and find out correlation between these and premenstrual syndrome to seek for active management methods.

In terms of general characteristics of the study subjects, $58.3 \%$ of the subjects experienced the first period before 13 years old, which was majority of them. This result is similar to Kim and Guen(17) that studied female middle school students and Sin and Jeoung(18) that studied female college students. The result indicates that improvement in recent nutrition intake and environmental effects seem to cause the age of first period getting younger.

In terms of duration of menstruation period, 56.3\% had irregular duration of period and $91.5 \%$ had less than 7 days of period. This result is similar to Son and You(15) that report 54.7\% had irregular duration of period and $52.6 \%$ had between 4 to 6 days of period. This shows that most women experience irregularity in their period due to physical and external environmental factors.

In terms the level of stress during menstruation period, $60.8 \%$ of the subjects were in the high stress level range. This result is a little bit different from Cha et al.(19) that reported most of the subjects were in the medium stress level range. However, most women feel menstruation as stress and various physical symptoms can occur with stress that one experiences in everyday life. In fact, symptoms of premenstrual syndrome occur fairly frequently and 
many women are affected by them. In addition, awareness about premenstrual syndrome is very low and women rarely consult with doctors(20).

In 2008, domestic premenstrual dysphoric disorder prevalence rate, effects on everyday life, and its treatment condition were surveyed on childbearing aged women. A thousand survey subjects were randomly selected according to population ratio of region and age. Based on the criteria suggested by American College of Obstetricians and Gynecologists, $32.1 \%$ of women experience premenstrual syndrome, and premenstrual dysphoric disorder prevalence rate was $2.8 \%$ (21). This suggests that serious premenstrual syndrome affects everyday life and social activities resulting in negative impact on women's lives. Therefore, it is critical to emphasize the importance of prevention and symptom management of premenstrual syndrome.

In the previous study that categorized female college student's premenstrual syndrome into 8 sub-categories(22), most frequent symptom was pain followed by negative emotion, behavioral change, water congestion, arousal, response of autonomic nervous system, lack of control ability, and decreased concentration. In this study, correlation between stress caused by menstruation and the factors of premenstrual syndrome such as negative emotion, digestive system change, behavioral change, pain, decreased concentration, water congestion, skin change, and response of autonomic nerve system was statistically significant static correlation. In another study, the severe the premenstrual syndrome is, the higher the possibility to have depression(23). This indicates one appeals to have more premenstrual syndrome as one gets more stress indicating stress and premenstrual syndrome is closely related. In addition, menstruation pain tends to increase as stress level increases(19) indicating there is relationship between stress and menstruation pain. Therefore, various programs that can manage menstruation pain should be developed for women who suffer from premenstrual syndrome.

This study has its limit as it is difficult to apply to all female college students because this study randomly selected the subjects from a certain area. In addition, the subjects had different menstruation period at the time of investigation which can cause difference in the memory and experience of symptoms. Therefore, it is necessary to keep menstruation period journal to predict one's own premenstrual syndrome period and its level of symptoms so that prevention programs can be generalized for subjects in all ages.

\section{CONCLUSION}

The purpose of this study is to understand the relationship between female college students' stress level and premenstrual syndrome so that it can provide baseline data on how to cope with it. The study subjects are 250 female college students in Gyungbook area. This study chose 199 appropriate subjects and collected data. As per general menstrual phases, this study investigated the age when one had her first period, regularity and duration of period, and amount of menstruation. It used a measurement tool to measure stress level and premenstrual syndrome. The study result is as follows.

1. In terms of general menstruation phase, most of the subjects experienced their first period before 13 years old. The period was irregular, duration of period was less than 7 days, 123 had normal amount of bleeding, and 121 had over 2.4 high stress level during the period.

2. In terms of the correlation between the stress caused by menstruation and premenstrual syndrome, each showed significant and static correlation( $\mathrm{p}<.01, \mathrm{p}<.001)$. Especially, correlation between digestive system and response of autonomic nervous system was .966, negative emotion and behavioral change was .635, and negative emotion and pain was .614 which were fairly high.

3. In the regression analysis of premenstrual syndrome according to the level of stress, response of autonomic nervous system had the most effect in the low stress group while behavioral change, negative emotion, pain, decreased concentration, water congestion, response of autonomic nervous system, and skin change had the most effect in the high stress group. They were all statistically significant(p<.001).

Based on the above results, higher stress level and premenstrual syndrome are highly related in some female college students. Therefore, it is necessary to develop various programs that can prevent and manage premenstrual syndrome through stress management. 


\section{REFERENCES}

1. Rizz D, Mosallam M, Alyan S, Nagelkerke N. Prevalence and impact of premenstural syndrome in adolescent schoolgirls in the United Arab Emirates. Acta Obstetricia et Gynecologica 2006; 85(3): 589-598.

2. Janca A, Hiller W. ICD-10 checklists-a tool for clinicians' use of the ICD-10 classification of mental and behavioral disorders. Compr Psychiatry. 1996; 37: 180-187.

3. Takeda T, Tasaka K, Sakata M, Murata Y. Prevalence of premenstrual dysphoric disorder in Japanese women. Arch Womens Ments Health 2006; 9: 209-212.

4. Kim HO, Lim SW, Woo HY, Kim KH. Premenstrual syndrome and dysmenorrhea in Korean adolescent girls. Kor J Obstet Gynecol 2008; 51(11): 1322-1329.

5. Jeong BS, Lee C, Lee JH, Seo MK, Han OS, Kim CY. Prevalence of premenstrual syndrome and premenstrual dysphoric disorder among korean college women. Kor J Neuropsychiatr. 2001; 40(4): 551-558.

6. Cosgrove L, Riddle B. Construction of feminity and experiences of menstrual distress. Women Health, 2003; 38(3):37-58.

7. Shin MA. A structural model of premenstrual symptom in female college students. Hanyang Univ. Unpublished doctoral dissertation. 2005

8. News Weekly. Premenstrual syndrome places heavy health and economic burdens on society through reduced work productivity and increased healthcare wisits and costs. PharmacoEconomics \& Outcomes News 2003; 42(3): 7-9.

9. Koo BW, Lee KW. Lee YG, Kwon JY, Han HD, Kim DH. A clinical study of premenstrual syndrome. Obstet Gynecol Sci 1990; 33: 1436-1444.

Kim HJ, Kim YS, Lim EM. A study on correlation

10. between stress and menstruation among lowincome women. J Kor Orien Gynecol 2009; 22(4): 136-149.

11. Kim MJ. Relationship between stress and menstrual patterns of female college students in Seoul. J Ewha Nurs 2007; 41: 99-118.
12. Jang HJ, Multicorrelation study on the change of menstrual cycle affected by stress and obesity. J Kor Orien Gynecol 2009; 22(4): 102-109.

13. Cho JH, Kim DI, Kang HC. The correlation analysis of factors related to PMS through survey. J Kor Orien Gynecol 2006; 19(4): 174-204.

14. Moos RH. The development of menstrual distress questionnaire. Psychosom Med. 1968; 30: 853-867.

15. Son YJ, You MA. Relationships between psychological factors and premenstrual syndrome symptoms in academic female high school. Kor J Health Promol Dis Prev 2008; 8(1); 8-16.

16. Chau JPC, Chang AM, Effects of an educational programme on adolescents with premenstrual syndrome. Health Educ Res 1999; 14(6): 817-830.

17. Kim HW, Kwon MK. A study of menstruation of middle school students. Kor J Women Health Nurs 2005; 11(2): 148-155.

18. Shin MA, Jeong MH. The relationship between premenstrual syndrome and sex role of college students. J Kor Acad Community Health nurs 2006; 17(1): 125-133.

19. Cha JH, Kim YS, Lim EM. A study on menstrual pattern and dysmenorrhea related factors of firstyear women college students. J Kor Orien Gynecol 2010; 23(4): 117-129.

20. Choi D, Lee DY, Lehert P, Lee IS, Kim SH, Dennerstein L. The impact of premenstural symptoms on activities of daily life in korean women. $\mathrm{J}$ Psychosom Obstet Gynaecol 2010; 31(2): 10-15.

21. Kim IH, Park HS, Lee HH, Chung SH. Premenstural syndrome and dysmenorrhea in the career somen at busheon city. Korean J Obstet Gynecol 2011; 54(9): 523-528.

22. Hwang HJ, Kim YM. A study of premenstrual syndrome and the nutritional intake of college women residing in Busan metropolital city. Korean $\mathrm{J}$ Community Nutr 2002; 7(6): 731-740.

23. Kim HO, Lim SW, WooHY, Kim KH. Premenstual syndrome and dysmenorrhea in korean adolescent girls. Korean J Obstet and Gynecology 2008; 51(11): 1322-1329. 